\title{
La vulnerabilidad en El Salvador frente al derecho a un ambiente sano
}

\section{Resumen}

La vulnerabilidad en El Salvador, como resultado del desorden territorial y el cambio climático en el planeta, está afectando a todas los ámbitos donde el ser humano actúa. Es común observar la proliferación de cárcavas, la producción de deslaves o los peligrosos cambios en los procesos climáticos. Estos fenómenos ocasionan a su vez alteraciones en la salud de las personas, interrumpen las rutinas diarias de estas y dibujan una huella ambiental desfavorable para el desarrollo de la sustentabilidad.

\section{Palabras clave}

Vulnerabilidad-aspectos ambientales, cambio climático, medio ambiente, legislación-El Salvador, desarrollo sostenible-derechos humanos.
Carolina Lucero Morán

Docente Utec

carolina.moran@utec.edu.sv

\section{Abstract}

As a result of climate change and a territorial mess in the planet, vulnerability in El Salvador is affecting all areas of human life. It is common to see the proliferation of gullies, landslides, or the dangerous changes in climate processes. These phenomena cause, in turn, alterations in people's health, interrupt their daily routines, and leave an adverse environmental mark for the development of sustainability.

\section{Keywords}

Vulnerability-environmental aspects, climate change, the environment,-legislation-, sustainable developmentEl Salvador.

\section{Introducción}

El desarrollo del tema de la vulnerabilidad ha estado tradicionalmente en manos de otras ramas de las ciencias (tanto exactas como sociales), las cuales han dedicado ingentes esfuerzos por tratar el tema y brindar respuestas efectivas (Aguilar \& Iza, 2009).

En torno al tema, la iniciativa Environmental Vulnerability Index define lo siguiente: "Vulnerabilidad se refiere a la tendencia a ser dañado. El concepto opuesto es la elasticidad; en otras palabras, la habilidad para resistir o recuperarse de un daño. Así cuando hablamos de vulnerabilidad, estamos automáticamente pensando también en elasticidad, pues ambos conceptos no son sino las dos caras de una misma

\footnotetext{
1 Docente investigadora de la Facultad de Derecho de la Universidad Tecnológica de El Salvador (Utec). Especialista Derecho Ambiental. Coordinadora de la unidad de Investigación Jurídica.
} 
moneda. De modo que algo que sea vulnerable, lo será en tanto deje de ser elástico, y viceversa".

Lavell (1999) da un ejemplo de esta visión dual, definiendo desastre, indicando que es "una ocasión de crisis o estrés social, observable en el tiempo y en el espacio, en que sociedades o sus componentes (comunidades, regiones, etc.) sufren daños o pérdidas físicas y alteraciones en su funcionamiento rutinario, a tal grado que exceden su capacidad de autorrecuperación, requiriendo la intervención o cooperación externa".

Aguilar \& Iza (2009) agregan que la idea de vulnerabilidad/ elasticidad se aplica tanto para entidades físicas (personas, ecosistemas o áreas costeras) como para conceptos abstractos (sistemas sociales, económicos o países). Los factores que causan daños son conocidos como amenazas o peligros, cada uno de los cuales se encuentra asociado con algún nivel de riesgo o posibilidad de que acaezca. Cabanellas (1997) define riesgo como contingencia, probabilidad, proximidad de un daño.

\section{Bienes jurídicos afectados}

Los bienes jurídicos afectados por la vulnerabilidad son la vida, regulada en el Art. 2 de la Constitución, y el medio ambiente (Art. 117), si bien como tal el derecho a un ambiente sano no está tutelado en esta. Gallardo (2003) señala que el medio ambiente es un bien común de la humanidad.

Aunque se hacen algunos esfuerzos para proteger los recursos naturales en El Salvador, la persona humana es la principal depredadora. Encuentra respaldo para destruir en el Art. 25 de la Declaración Universal de Derechos Humanos, que dice así: "Toda persona tiene derecho a un nivel de vida adecuado que le asegure, así como a su familia, la salud y el bienestar". Así mismo, el Art. 65 de la Constitución reza lo siguiente: "La salud de los habitantes de la República constituye un bien público. El Estado y las personas están obligados a velar por su conservación y restablecimiento".

Hesperian (2005) señala el derecho al medio ambiente como el goce de la buena salud, producto de mantener buena limpieza y desechar los residuos humanos.

El Art. 69 de la Constitución sostiene que "el Estado controlará la calidad de los productos alimenticios y las condiciones ambientales que puedan afectar la salud y el bienestar". El Art. 117 afirma que "es deber del Estado proteger los recursos naturales, así como la diversidad e integridad del medio ambiente, para garantizar el desarrollo sostenible".

\section{Desarrollo sostenible y nivel de vida adecuado}

El desarrollo sostenible, según el Informe de Bruntland, se entiende como desarrollo sustentable "que satisface las necesidades del presente sin comprometer las necesidades de las futuras generaciones". Este concepto ha establecido cambios importantes en cuanto a la idea de sustentabilidad, principalmente ecológica, y a un marco que da también da énfasis al contexto económico y social del desarrollo.

No obstante, el daño contra el medio ambiente continúa: tala de árboles, gases industriales (reglamento SAO), fábricas, quemas incontroladas, basura, desorden territorial, construcciones desordenadas, uso de suelos, ríos y lagos como cuerpos receptores (Art. 3, Reglamento especial de aguas residuales), etc., ejemplos de cómo se hace valer el derecho "a un nivel de vida adecuado", atentando directamente contra el bien jurídico de la vida y del medio ambiente.

\section{El derecho humano al medio ambiente sano}

La Declaración Universal de los Derechos Humanos (1948) desveló el nacimiento de los derechos colectivos o de la solidaridad en 1948 (Morán, 2012), "asegurando medidas progresivas de carácter nacional e internacional para su reconocimiento y aplicación universales y efectivos."

Hacia 1968, la ONU, recomendó la conferencia sobre "Ios problemas del medio humano", advirtiendo "el deterioro constante y acelerado de la calidad del medio humano" y "Ios efectos consiguientes en la condición del hombre, su bienestar físico, mental y social, su dignidad y su disfrute de los derechos humanos básicos, tanto en los países en desarrollo como en los desarrollados". Más tarde, la Declaración de Derechos Humanos Emergentes (2004) reconoce en el artículo 3, "el derecho de todo ser humano y de los pueblos que se integran a vivir en un medio ambiente sano, equilibrado y seguro, a disfrutar de la biodiversidad".

El Instituto de Derechos Humanos de Catalunya (IDHC, 2005) menciona que las únicas excepciones significativas, por tratarse de textos internacionales jurídicamente vinculantes, 
son la Carta Africana de los Derechos Humanos y de los Pueblos, adoptada en Nairobi en 1981, y el Protocolo a la Convención Americana de Derechos Humanos en materia de derechos económicos, sociales y culturales, adoptado en San Salvador en 1988. El primero recoge el derecho de "todos los pueblos a disfrutar de un medio ambiente satisfactorio y global, propicio para su desarrollo", y el segundo reconoce, en su artículo 11, que "toda persona tiene derecho a vivir en un medio ambiente sano y a contar con servicios públicos básicos". No obstante, el IDHC señala que en ambos casos se trata de convenios de alcance regional cuyo impacto, en la práctica, es además limitado. Para Herrero (2002), el problema es que en la Carta Africana "no se trata de un derecho individual sino colectivo (...) la colectividad beneficiaria es bastante difícil de delimitar". El Protocolo de San Salvador, aunque recoge un derecho al medio ambiente sano, este se excluye del recurso ante la Corte Interamericana de Derechos Humanos (Herrero, 2002).

\section{El derecho ambiental}

El camino del Derecho Ambiental ha sido largo; desde el Imperio austrohúngaro hasta la Conferencia de Estocolmo 1972. Siguen organismos como el Programa de Naciones Unidas para el Medio Ambiente (PNUMA, 2005) (UNEP por sus siglas en inglés) y Cumbre de la Tierra, 1988 (ONU, 1995). La Declaración de Lisboa (1988) propone vivir en un ambiente sano y ecológicamente equilibrado para elevar su nivel de vida y su desarrollo (Ojeda y Hernández, 2009).

Continúa la Comisión Mundial para el Medio Ambiente y Desarrollo, (CMMAD), la Conferencia de la ONU sobre el Medio Ambiente y el Desarrollo, la Comisión sobre el Desarrollo Sostenible, Agenda 21 y el desarrollo sostenible; la Declaración de Río sobre el Medio Ambiente y el Desarrollo, y la Declaración de principios relativos a los bosques, para apoyar el manejo sostenible de los bosques a nivel mundial. Le siguen la Convención Marco de la ONU sobre el Cambio Climático y el Convenio sobre la diversidad biológica (MARN, 2010).

Uno de los principios de la Comisión Mundial sobre el Medio Ambiente y Desarrollo establece: "Todos los seres humanos tienen el derecho fundamental a un medio ambiente adecuado para su salud y su bienestar".

Velasco (1990) agrega la Convención de lucha contra la desertificación, la Cumbre Mundial (Río+10), la Cumbre de Johannesburgo de 2002, entre otros. Esfuerzos que establecen para los Estados miembros "la responsabilidad colectiva de promover y fortalecer, en los planos local, nacional, regional y mundial, el desarrollo económico, desarrollo social y la protección ambiental, pilares interdependientes y sinérgicos del desarrollo sostenible".

\section{El ser humano: enemigo del ser humano}

Si bien en la actualidad el ser humano considera uno de sus enemigos al cambio climático, por cuanto le resta estabilidad, debe reflexionarse que el mayor enemigo del planeta es el ser humano y su interferencia antropogénica, por cuanto en la búsqueda de la protección de sus derechos humanos ha afectado grandemente los derechos de la Tierra: del suelo, del aire, del agua y de la biota.

La Declaración de Estocolmo estatuyó que "el hombre tiene el derecho fundamental a la libertad, la igualdad y el disfrute de condiciones de vida adecuadas en un medio de calidad tal que le permita llevar una vida digna y gozar de bienestar, y tiene la solemne obligación de proteger y mejorar el medio ambiente para las generaciones presentes y futuras" (ONU, 1995). ¿Por qué no cumple con su obligación?

Huici y Elizalde (2008) indican que el derecho a un medio ambiente sano es la íntima vinculación del medio ambiente con el nivel de vida en general. Una condición sine qua non para el disfrute y ejercicio de los demás derechos.

En este contexto, El Salvador debe buscar la protección de un medio ambiente adecuado o de calidad. Se debe restaurar el planeta, para que desde ahí se pueda acceder a ese medio ambiente sano que el mundo se merece. Solo así se evitará la vulnerabilidad.

\section{Referencias}

Aguilar, G., \& Iza, A. (2009). Derecho Ambiental en Centroamérica, Tomo II. Gland, Suiza: UICN.

Brundtland (4 de agosto de 1987). "ONU General Assembly". Recuperado el 12 de julio de 2016 de Report of the world commission on environment and development, http://daccess-dds-ny.un.org/ doc/UNDOC/GEN/N87/184/67/IMG/N8718467. pdf?OpenElement

Cabanellas, E. (1997). Diccionario Jurídico Elemental. Buenos Aires: Heliasta. 
CIDH (12 de diciembre de 1988). “Comisión Interamericana de Derechos Humanos". Recuperado el 22 de julio de 2016 de "A-52: Protocolo adicional a la Convención Americana sobre derechos humanos en materia de derechos económicos, sociales y culturales 'Protocolo de San Salvador'", http://www.cidh.oas. org/Basicos/basicos4.htm

CNUMAD (10 de octubre de 1992). "Conference on environment and development". Recuperado el 14 de julio de 2016 de Earth Summit, http://www.un.org/geninfo/bp/enviro.html

Gallardo, H. (2003). "Nuevo Orden Internacional, derechos humanos y Estado de Derecho en América Latina". Crítica Juridica (22), 260.

Herrero, A. (2002). La protección internacional del Derecho. Barcelona: IDHC.

Hesperian, F. (2005). Saneamiento y limpieza para un ambiente sano. Nueva York: Programa de Naciones Unidas para el desarrollo.

Huici, L., \& Elizalde, M. (2008). “Derechos humanos y cambio climático". Derechos Humanos Emergentes.

IDHC (13 de mayo de 2005). "Institut de Drets Humans de Catalunya". Catalunya: IDHC. Recuperado el 17 de julio de 2016 de Derechos humanos emergentes, http://www.idhc.org/esp/1241_ddhe.asp

IDHC (2008). Derechos humanos y cambio climático. BarceIona: Institut de Drets Humans de Catalunya.

Lavell, A. (1999). "Ciencias Sociales y desastres naturales en América Latina: un encuentro inconcluso". EURE, 73-84.

MARN (09 de mayo de 2010). "Ministerio de Medio Ambiente y Recursos Naturales". Recuperado el 12 de julio de
2016 de Convenio Marco de las Naciones Unidas para el Cambio Climático, http://www.marn.gob. sv/index.php?option=com_content\&view=article\&i $\mathrm{d}=191$ \& temid $=250$

Morán, C. (2012). “El derecho a la protección y cuidados especiales orientados a la sexualidad de adolescentes salvadoreños". El Salvador: Utec.

Ojeda, Z., \& Hernández, M. (2009). "El derecho al medio ambiente: su regulación constitucional". OIDLES, Junio, Vol. 3, No.6.

ONU (05 de agosto de 1995). Documentación de las Naciones Unidas: Guía de investigación. Recuperado el 12 de julio de 2016 de El Medio Ambiente, http:// www.un.org/Depts/dhl/spanish/resguids/specenvsp.htm

Sánchez, D. (2007). Repensar derechos humanos. De la anestesia a la sinestesia. Sevilla: MAD ISBN 84-6657152-3.

Serrano, I. (23 de octubre de 2012). "Recuperan cuerpo de tercera víctima que fue arrastrada por correntada". La Página, http://www.lapagina.com.sv/ampliar. php?id=72838.

Unep (12 de abril de 2005). United Nations Environment Programme. Recuperado el 15 de julio de 2016, de Unep environment for development, http://www. unep.org/

Vasak, K. (1979). La división de derechos humanos en tres generaciones. Estrasburgo, Francia: Instituto Internacional de Derechos Humanos.

Velasco, J. (1990). "Aproximación al concepto de los derechos humanos". Anuario de Derechos Humanos, 269-284 ISSN 0212-0364. 